\title{
Germany struggles with organ transplantation
}

For more than 15 years, Germans have been debating laws regulating organ transplantation. After several competing drafts, members of the German Bundestag are now inching toward a compromise. That compromise, however, satisfies neither transplant specialists nor the more than 1,200 members of the Arbeitsgruppe Organspende (AGO) who represent organ recipients and their relatives. Both sides say that none of the various proposals discussed by the Bundestag will alleviate the chronic shortage of organs that ultimately claims 1,500 lives in Germany annually. The debate is further sharpened by an ongoing and highly public dispute over whether brain death is an acceptable criterion in determining death for organ-harvesting purposes.

Up to the end of last year, a total of 30,635 kidneys, 4,135 hearts, 4,002 livers, 473 pancreas and 435 lungs have been transplanted in the country since the late 1960s. Although at least 4,000 donors annually would be needed to match demands, presently only 2,000 of the 900,000 deaths per year are willing and suitable donors.

"If it wasn't for the high willingness of donating organs in neighboring countries, a large number of transplantations could not be done here at all," acknowledged Secretary of Health Horst Seehofer in a recent speech before the Bundestag. Since the establishment in 1967 of Eurotransplant (a not-for-profit organization that matches donors and recipients across all of Europe), a total of 1,500 organs have been imported into Germany. "We are thankful for that, but in the long run we can not go on like this. It would be immoral. Hence, it is our duty to increase the willingness of the population to donate organs," Seehofer said.

That could easily be achieved if Germany would adopt laws on the basis of a "contradiction-solution," argues Anton Liebermann, recipient of a heart transplant and a spokesman for AGO. Under that plan, organs may be harvested and used for transplantation from any dead person unless that person has specifically opposed such a move during his lifetime. Liebermann points to Belgium and Austria, where such laws are in place and where the transplan-

tation rates on a per-capita basis are twice as high as in Germany. That idea, however, found virtually no support among parliamentarians, despite heavy lobbying on the part of AGO.

Another proposal that would make transplantations illegal unless the donor or, for lack of a documented will, his relatives consent to that measure was recently drafted by Rudolf Dreßler, deputy chief of Germany's leading opposition party, the Social Democrats (SPD), in close collaboration with Seehofer and Dieter Thomae of Germany's Liberal Party (FDP). "It is a sensible [issue], that has to be based on the widest social and political agreement possible," explains Seehofer. "Demands or pressures on people are detrimental to nopende

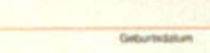

n.2 watom

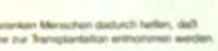

misum om

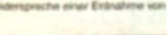

(06102) 39999

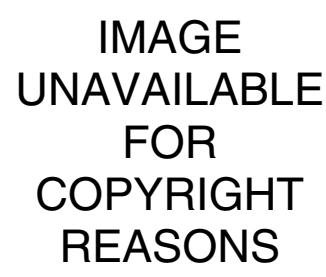

Secretary of Health Horst Seehofer (above, right). A German organ donor card (left).

our efforts." However, any current agreement among parliamentarians is limited to the basic acknowledgment that more organs are needed for transplantations and that there should be a law regulating the details within this year. And, in stark contrast with most political confrontations, attitudes do follow party lines.

Another proposal, currently discussed under the label of "strict consent," has been introduced by Social Democrats Wolfgang Wodarg and Herta DaublerGmelin, but is also finding support from some members of the ruling coalitiongovernment of Christian-Democrats (CDU) and their junior partners CSU and FDP. Strict consent would leave the decision with the potential donor exclusively, but the proposal refrains from making this decision mandatory.

Matters are even more complicated in reaching a compromise, because the use of "brain death" as a definite marker for the end of human life is still disputed among the members of the Bundestag. While the differences in opinion again are not strictly coincidental with party lines, members of Bundnis 90/Die pital.
Grunen in particular tend to believe that "a person who is brain-dead is still in the process of dying," according to the party's Monika Knoche. Most legal experts assert that if this were indeed the case, it would mark the end of all transplantations in Germany, because the procedure would amount to ending a life whose integrity is guaranteed by the country's most basic law, the Grundgesetz.

It is a passionate issue that has spread beyond the walls of the Bundestag. Wide coverage has been given by the media to people like Theologian Jürgen in der Schmitten, who provoked members of the transplantation teams by calling them "vivisectionists." Talk shows and highly publicized but unproven stories of a secret organ trade add to the confusion among Germans, some of whom see carrying donor cards as an additional risk to their lives. "These are the effects of some selfappointed moral philosophers, trying to talk away the scientifically sound fact of brain death," fumes Walter Land, who heads the transplantation center at Munich's Groshadern Hos-

Partially to counter the growing uneasiness within large parts of the population, a joint statement by four German scientific societies has been published. Signed by the presidents of the societies for anesthesiology, neurosurgery, neurology and physiology, respectively, the statement says that "a human whose brain has completely and irreversibly stopped functioning is dead." Just days before the debate in the Bundestag got under way, the country's medical association (Bundesarztekammer) again stated that there was "no rational reason to doubt the criterion of brain-death."

While an end to the dispute is not in sight, the ministry of health is looking for less formal ways to ease the shortage. A public relations blitz financed by the ministry will plead with Germans to give the "gift of life," a strategy that, ironically, the ministry hesitated to support when AGO attempted it earlier this year.

MiChaEL SiMM Munich, Germany 